\title{
ECOTOXICOLOGICAL ASSESSMENT OF DRILL CUTTINGS OF OIL DEPOSITS BY BIOTESTING METHODS
}

\author{
Ludmila P. Kapelkina \\ Marina V. Chugunova \\ Tamara V. Bardina \\ St.-Petersburg Scientific Research Center for Ecological Safety RAS, Russia
}

\begin{abstract}
Complex multi-component wastes include sewage sludges of treatment plants, industrial and domestic wastes, as well as drill cuttings. In the oil-producing regions, they are the main large-capacity waste. Chemical composition of drill cuttings is conditioned by mineralogical composition of drilled solids and properties of chemicals used in drilling. Since the composition of the latter is not always known (in some cases it can be protected by patent), it is almost impossible to establish the danger or safety of drill cuttings to the environment, based only on the use of chemical analysis methods. Therefore, the only way allowing to assess the cumulative toxicity of drilling waste is biotesting which is based on the determination of reaction of the living organisms to content of the pollutant in the tested sample.
\end{abstract}

While assessing the toxicity of drill cuttings by biological methods, scientists often test the aqueous extract to which the soluble forms of pollutants tend to migrate (eluate biotesting method), and various hydrobionts are used as the tested organisms. However, for adequate assessment of multicomponent solid mediums apart from the eluate methods, it is necessary to use substrate biotesting that provides direct contact of test organism with the tested sample, and thus allows to establish the level of cumulative impact rendered by the contaminants present in the solid substrates, on the living organisms. Therefore we, especially for the purpose of drill cuttings evaluation, have developed substrate methods in which higher plants and natural complex of microorganisms contained in the sludge itself are used as the tested organisms.

The goal of our researches was ecotoxicological assessment of drill cuttings in the oil fields of the Western Siberia, applying methods of substrate and eluate biotesting. For this purpose, test organisms at various levels of organization were used: microorganisms, aquatic organisms, higher plants, and mammals.

It has been established that the studied drill cuttings are hypotoxic or practically nontoxic. According to current statutory regulations of the Russian Federation, they can be classified within IV and V hazard classes. The results of the conducted researches indicate the 
Linnaeus ECO-TECH '14,

Kalmar, Sweden, November 24-26, 2014

advisability of applying, for the purpose of environmental assessment of drill cuttings, of both eluate and substrate biotesting methods.

\section{KEYWORDS}

Drill cuttings, ecotoxicological assessment, biotesting methods.

\section{INTRODUCTION}

Process of exploratory drilling in gas fields areas causes the appearance a big amount of waste - drill cuttings (DC), consisting of drilled out ground and chemicals from drilling solutions. A question of toxicity or safety of DC is still being discussed. During 1960-80-s DC were considered very toxic. But later data was gained showing that DC do not have any influence or have low negative influence on the environment and their low concentrations even have positive effect on fertility and physiological state of plants [1, 2]. It was even suggested to use DC for the purposes of recultivation of disturbed lands in the regions of gas and oil exploitation [3]. For taking the decision about acceptability of using DC for recultivation of disturbed lands a scientific proof of their ecological safety is necessary.

Traditionally for the ecological control of DC and other wastes chemical analytical methods are used. However, evaluation of potential ecological hazard of such complex substrata as DC, only at the base of quantitative characteristics of pollutants is impossible. Firstly, there is certain doubt in results obtained by instrumental methods of determination of toxic substances. For example, in Russia there are three standard methods of determination of presence of oil and its products in the soils: luminescent, IR-spectroscopic and gravitational. Results obtained by different methods are not the same.

Secondly, quantitative characteristics of pollutants in substrata determined by chemical analytical methods do not always reflect their real toxic effect. For example, the influence of heavy metals on living organisms is determined not only by their absolute concentration but also by solubility of metal form, soil type, grain composition, $\mathrm{pH}$, of organic matter content, etc. Besides, it is very difficult with chemical methods to cover the variety of pollutants present in soils and technogenic grounds

Therefore it is necessary to use also biological methods (along with chemical analytical) for assessing the state of environment. Biotesting is one of biological methods. A princip of biotesting is the determination of living organisms reaction on the degree of technogenic impact and concentration of pollutants in substrate. Usage of both chemical and biological methods together allows increase trustworthiness of the research and obtain really cumulative evaluation of the ecological condition of the studied objects.

Nowadays there are dozens different methods of biotesting of waste, soils, grounds. Most of them are based on analysis of water extracts. Different aquatic organisms (algae, Daphnia, infusoria, aquaria fish egg, mosquito larvae etc) are commonly used as test organisms for evaluating of toxicity of DC by biotesting water extracts (eluate method). According to our investigations and literature data on biotesting, the most sensitive of all toxicological eluate methods is Daphnia-survival biotest.

However in our opinion for the adequate evaluation of multicomponent solid mediums (soils, grounds, waste) apart from the eluate methods, it is necessary to use substrate biotesting, in 
other words, analysis directly on the sample. It provides direct contact of test organism with the test sample and allows determine the cumulative impact of pollutants present in solid substrata, in particular in DC, on living organisms. It is known that no one species is universal indicator. Therefore for ecotoxicological evaluation of DC it is necessary to provide biotesting with several test organisms of different evolutional levels.

One of the most important characteristics of quality of soils, grounds and waste is the biomass of growing on them plants. Another important indicator for evaluation of solid media is its microbial flora. It is caused by the fact that microorganisms providing mineralization of organic matter are the main part in the process of elements circulation in biosphere. Besides, microorganisms, as sensitive indicators of biological conditions of various solid media, are optimal test-cultures for biotesting. Contact microbial tests which are used nowadays in Russia are based on the evaluation of influence of contaminated substrata on test organism, placed inside substrata. It is known that in solid waste, for example in DC, significant amounts of living microflora can be present. It allows to use the complex of microorganisms present in DC as test-culture for diagnostics of their vitality.

The aim of our research was ecotoxicological evoluation of DC by methods of substrate and eluate biotesting using test-organisms of different evolutional level (microorganisms, hydrobionts, higher plants, mammals)

\section{MATERIALS AND METHODS}

The objects of the study were DC, which form in process of oil prospecting drilling throughout the West Siberian Arctic, containing resides of drilling chemicals.

Most of the studied DC had clayey grain structure, had alkaline reaction $(\mathrm{pH}=8,0-9,1)$, usually not saline or slightly saline, contained movable forms of nutrients, phosphorus, and potassium. Concentration of crude oil did not exceed $3 \%$.

Several DC samples contained increased compare to accepted in Russia standards (allowed concentration and maximal allowed concentrations) total quantities of heavy metals. However, chemical analysis on determination of movable forms of heavy metals in acetateammonium buffer solution, showed that their concentration, as a rule did not exceed established standards - maximal allowed concentrations of movable forms. Respectively, heavy metals were in hardly soluble form, which is hardly available for living organisms form and therefore they were not toxic for living organisms.

According to the results of previous research and literature data for the evaluation of DC we have compiled and tested a set of test-organisms consisting of microorganisms, higher plants (oats, wheat), aquatic organisms (Daphnia, egg of aquaria fishes), mammals (rats).

Substrate microbial tests were performed according to the method specially elaborated for DC [4]. As a test-culture a complex of micro-organisms living in DC was used. The level of toxicity was determined according to the change of biological reaction of microbial flora of DC on disturbance compare to the control. As a trigger for the response biological reaction of DC, glucose in concentration $1 \%$ of dry weight of substrata was used. Intensity of response reaction was determined according to the excreted amount of $\mathrm{CO}_{2}$, measured daily during several days. The measure of the soil's biological response to the addition of glucose was the maximal energi level of the process of $\mathrm{CO}_{2}$ excretion. Criteria for the determination of hazard class was statistically significant differences between maximal diurnal level of respiration of 
DC's microflora and microflora of control substrata after addition of glucose. Intensity of CO2 excretion was determined by adsorption method.

For the complex ecotoxicological assessment of DC's water extract, methods of toxicological analysis, included in Federal Register, with Daphnia [5], Infusoria [6] and aquaria fishes [7, 8] were used;

In experimental assessment of DC's impact on aquatic organisms, the degree of delution of the water extract which do not have toxic effect was determined. Criteria of acute toxicity of the extract on Daphnia is 50\% mortality of Daphnia in testing samples compare to control during the period of up to 96 hours. According to achieved results hazard class of DC was determined.

Parameters of behavioral reaction of Infusoria were determined with the instrument "Biotester-2". Toxicity was determined according to the scale from 0 to 1.

Criteria of toxicity on aquaria fish was survival of fish egg and young fish in the DC's aqueous extract.

Substrate phytotesting directly in DC samples were carried out according to the methodology elaborated in Saint-Petersburg Research Center for Ecological Safety [9]. In substrate biotesting seeds of soft wheat were used. According to decrease in germinating capacity and poorer growth of roots compare to control, hazard class of waste was determined. As a control for biotesting natural non-toxic clay was used.

Study of acute and chronic toxicity of DC was performed also on mammals - on white rats. A wide spectrum of methods was applied to study toxicological, morphological and biochemical variables. Acute toxic effect of DC was studied by their injection into stomach in increasing doses. (5-13 g/kg). General condition, body weight, uptake of food and water, urine analysis, biochemical analysis of blood, detoxifying function of liver, plasma-coagulate haemostasis, cardio-vascular and respiratory systems; reflexes, structure of inner organs.

\section{RESULTS AND DISCUSSION}

\subsection{Microorganisms}

Studied DC were characterized by different biological activity. Activity in samples \#\# 1-8 exceeded the control 1,5-2 times (Table 1). High activity of these DC was caused by the specific of their chemical composition, namely high content of biophylic elements For example, concentration of movable phosphorus in these samples was comparable with such in chernozem soils. As it is mentioned in literature, biophylic elements can stimulate microflora of DC.

DC \#\# 1-8 did not have any toxic effect on microflora, moreover they notably stimulate its activity. Therefore they can be referred to the $\mathrm{V}^{\text {th }}$ hazard class - practically non-hazardous. DC \#5 and \#\# 9-11 were characterized by lower than the control biological activity (Table 2). Its decrease in the samples varied from $31.6 \%$ to $48 \%$ compare to control. According to toxicity scale these DC belong to the $\mathrm{IV}^{\text {th }}$ haszard class - low hazardous. 
Linnaeus ECO-TECH '14,

Kalmar, Sweden, November 24-26, 2014

Table 1. Change (\%) of biological activity of drill cuttings compare to controls (N).

\begin{tabular}{|c|c|c|c|c|c|c|c|}
\hline № DC & N & № DC & N & № DC & N & № DC & N \\
\hline 1 & $+53,9$ & 5 & $-35,9$ & 9 & $-38,9$ & 13 & $-45,5$ \\
\hline 2 & $+99,7$ & 6 & $+39,5$ & 10 & $-35,8$ & 14 & $-48,0$ \\
\hline 3 & $+59,6$ & 7 & $+81,4$ & 11 & $-34,5$ & 15 & $-31,6$ \\
\hline 4 & $+71,6$ & 8 & $+69,8$ & 12 & $-35,7$ & 16 & $-35,3$ \\
\hline
\end{tabular}

Decrease of biological activity in DC № 5, could be connected with low concentration of biophylic elements, especially phosphorus. Decrease of biological activity of DC №№ 9-16, most probably was caused not by their toxicity but by less favorable physical properties (high density of substrate) compare to natural clay.

\subsection{Aquatic organisms}

It was found out that extracts from the majority of studied DC samples were not toxic for Daphnia (Table 2). Toxicity found in aqueous extracts from DC \#\#14 and 15 disappeared after their 10-fold delution. Biotesting using Infusoria as test-organisms revealed that aqueous extracts of several samples were toxic for threm, but 100-fold delution displaced toxicity. (табл. 2).

Studied DC samples did not have hazardous impact on embryonal and post-embryonal development of aquaria fishes. Fish egg and young fish survival in aqueous extracts reached $100 \%$. Respectively aqueous extracts of all samples were non-toxic (Table. 2).

After experimental determination of hazard-class of DC according to toxicity of their aqueous extracts for three different representatives of aquatic organisms it was stated that the majority of samples belonged to the $\mathrm{V}$ hazard class - practically non-hazardous according to classification of the Ministry of Nature Resources of Russia [10] or to the IV hazard class low hazardous, according to classification of Health Protection Ministry of Russia [11].

Table 2. Influence of drill cuttings on aquatic organisms

\begin{tabular}{|c|c|c|c|c|c|}
\hline \multirow[t]{2}{*}{ № DC } & \multicolumn{2}{|c|}{$\begin{array}{l}\text { Criteria of acute toxicity } \\
\text { on Daphnia }\end{array}$} & \multirow[t]{2}{*}{$\begin{array}{l}\text { Mean value of } \\
\text { toxicity index on } \\
\text { Infusoria T }\end{array}$} & \multicolumn{2}{|c|}{$\begin{array}{c}\text { Overall \% of } \\
\text { survival of fish egg and } \\
\text { young fish }\end{array}$} \\
\hline & A \% & $t_{d}$ & & $\%$ & $t_{d}$ \\
\hline 1 & 0 & 0 & Not determined & 96,6 & 0,99 \\
\hline 2 & 0 & 0 & Not determined & 96,6 & 0,99 \\
\hline 3 & 0 & 0 & Not determined & 93,3 & 1,99 \\
\hline 4 & 0 & 0 & Not determined & 96,6 & 0,99 \\
\hline 5 & 13,3 & 1,99 & Not determined & 93,3 & 1,99 \\
\hline 6 & 20,0 & 4,96 & Not determined & 100,0 & - \\
\hline 7 & 0 & 0 & Not determined & 100,0 & - \\
\hline 8 & 0 & 0 & Not determined & 96,6 & - \\
\hline 9 & 0 & 0 & Not determined & 100,0 & - \\
\hline 10 & 6 & 0,71 & 0,12 & 100,0 & - \\
\hline 11 & 10 & 1,13 & 0,16 & 100,0 & - \\
\hline
\end{tabular}


Linnaeus ECO-TECH '14,

Kalmar, Sweden, November 24-26, 2014

\begin{tabular}{|l|c|c|c|c|c|}
\hline 12 & 20 & 1,5 & 0,15 & 100,0 & - \\
\hline 13 & 40 & 2,99 & 0,65 & 100,0 & - \\
\hline 14 & 60 & 8,98 & 0,66 & 100,0 & - \\
\hline 15 & 80 & 8,98 & 0,75 & 100,0 & - \\
\hline 16 & 40 & 2,99 & 0,58 & 100,0 & - \\
\hline 17 & 0 & 0 & 0,67 & 100,0 & - \\
\hline
\end{tabular}

\subsection{Higher plants.}

Results of biotesting of DC , performed in 2 stages, i.e. in different time are presented in Table 3.

According to the results of determination of acute toxic effect of DC on seed germination, all studied samples were classified as the $\mathrm{V}^{\text {th }}$ hazard- class - practically non-hazardous waste [10]. The only exception was sample № 5, which toxicity was caused by increased concentration of soluble salts $(\mathrm{KCl})$ This sample was referred to the III $^{\text {rd }}$ hazard-class moderately hazardous waste.

\subsection{Mammals}

Experimental results showed that injection of all studied DC samples directly into stomach of rats did not lead to death of animals and did not cause any pathology in their body or behavior, blood, body weight etc. Therefore all DC were referred to the IV hazard-class - low hazardous [11].

Table 3. Results of phytotesting of drill cutting samples.

\begin{tabular}{|c|c|c|c|c|c|c|c|}
\hline \multirow{3}{*}{ Sample Nr } & \multirow{2}{*}{\multicolumn{3}{|c|}{ Germination }} & \multirow{2}{*}{\multicolumn{3}{|c|}{ Root }} & \multirow{3}{*}{$\begin{array}{c}\text { Hazard class } \\
\text { a }\end{array}$} \\
\hline & & & & & & & \\
\hline & $\%$ & $\mathrm{~N}_{1}$ & $\mathrm{t}_{\mathrm{d}}$ & $\begin{array}{l}\text { Length, } \\
\text { mm }\end{array}$ & $\mathrm{N}_{2}$ & $\mathrm{t}_{\mathrm{d}}$ & \\
\hline \multicolumn{8}{|c|}{1 stage of phytotestung } \\
\hline Control & 81,7 & - & - & 29,2 & - & - & - \\
\hline DC-1 & 81,7 & 0 & 0,00 & 32,2 & $+10,3$ & 0,64 & $\mathrm{~V}$ \\
\hline DC-2 & 76,7 & $-6,2$ & 1,14 & 34,2 & $+17,1$ & 1,41 & $\mathrm{~V}$ \\
\hline DC-3 & 75,0 & $-8,2$ & 1,42 & 34,9 & $-19,5$ & 1,72 & $\mathrm{~V}$ \\
\hline DC-4 & 81,7 & 0 & 0,00 & 37,0 & $+26,7$ & 2,70 & $\mathrm{~V}$ \\
\hline DC-5 & 42,0 & $-48,6$ & 9,23 & 14,2 & $-51,4$ & 5,15 & III \\
\hline DC-6 & 75,0 & $-8,2$ & 1,14 & 23,8 & $-18,5$ & 1,85 & $\mathrm{~V}$ \\
\hline DC-7 & 76,7 & $-6,2$ & 1,14 & 35,4 & $+21,2$ & 2,06 & $\mathrm{~V}$ \\
\hline DC-8 & 75,0 & $-8,2$ & 1,42 & 31,3 & $+7,1$ & 0,45 & $\mathrm{~V}$ \\
\hline DC-9 & 75,0 & $-8,2$ & 1,57 & 27,8 & $-4,8$ & 0,45 & $\mathrm{~V}$ \\
\hline \multicolumn{8}{|c|}{2 stage of phytotesting } \\
\hline Control & 95,0 & - & - & 24,1 & - & & F \\
\hline DC-10 & 93,3 & $-1,79$ & 2,14 & 22,8 & $-5,39$ & 12,04 & $\mathrm{~V}$ \\
\hline DC11 & 85,0 & $-10,53$ & 4,24 & 36,7 & $+52,28$ & 0,20 & $\mathrm{~V}$ \\
\hline DC-12 & 91,7 & $-3,47$ & 2,67 & 21,6 & $-10,37$ & 6,05 & $\mathrm{~V}$ \\
\hline DC-13 & 90,0 & $-5,26$ & 4,90 & 24,9 & $+3,32$ & 7,56 & $\mathrm{~V}$ \\
\hline
\end{tabular}


Linnaeus ECO-TECH '14,

Kalmar, Sweden, November 24-26, 2014

\begin{tabular}{|l|l|l|l|l|l|l|l|}
\hline DC-14 & 93,3 & $-1,79$ & 1,41 & 35,2 & $+46,06$ & 0,10 & V \\
\hline DC-15 & 91,7 & $-3,47$ & 7,07 & 26,9 & $+11,62$ & 4,46 & V \\
\hline DC-16 & 88,3 & $-7,05$ & 4,95 & 23,9 & $-0,83$ & 3,92 & V \\
\hline DC-17 & 93,3 & $-1,79$ & 5,66 & 30,4 & $+26,14$ & 4,75 & V \\
\hline
\end{tabular}

$\mathrm{N}$ - change of test-variable influenced by DC in comparison with control, \%

\section{CONCLUSIONS}

Study on ecotoxicological assessment of drill cuttings revealed that in most cases they are practically non-toxic or low toxic. According to accepted in Russia legislative documents, they should be referred to IV and V hazard-class. Our results reveal the necessity of application both eluate and substrate methods for biotesting.

\section{REFERENCE}

[1] Sataev A.C., Dolgopyatova N.G., Kuzin Yu.Z. 1989: Environmental conservation during the bore-holls construction // Advances in machinery and technology for construction of gas and gas-condensate bore-holes. VNII Gas publications. Moscow. P.144-153. In Russian.

[2] Sedyh V.N., Ignat'ev L.A., Semenjuk M.V. 2004: Reaction of plants on the drill waste impact . Novosibirsk, "Nauka”. 103 p. In Russian.

[3] Berezin A.E., Bazanov V.A., Parshina N.V. 2013. Use of drill cuttings for the recultivation of disturbed land in the regions of oil exploitation // Natural-technical complexes: Recultivation and sustainable development. Conference proceedings. Novosibirsk. P. 279281. In Russian. In Russian.

[4] FR.1.39.2004.01061. 2004. Method of determination of hazard-class of drill cuttings. 2004. М-БШ-01-2004. In Russian.

[5] FR. 1.39.2007. 03222. 2007. Method of determination of toxicity in water and aqueous extracts from soils, sewage sediments and waste by mortality and change in fertility of Daphnia. Moscow. Akvaros. 51 p. In Russian.

[6] FR. 1.31.2005.01881. 2010. Method of determination of toxicity of water samples by express method using ”Biotester”. Saint-Petersburg, "Spektr-M”. 19p. In Russian.

[7] RD-18-02-90. 1991. Methodic guidance on biotesting of water.Moscow: Goskompriroda USSR. 46 p. In Russian.

[8] Methodic recommendations on ellaboration of water quality standards for water reservoirs with importance for fisheri, including norms of maximal allowed concentrations of hazardous pollutants in waters of water reservoirs with importance for fisheri. Bulliten of legislative documents of federal authorities. 2009, N 43. In Russian.

[9] FR.1.39.2004.01104. 2004. Method of determination of hazard-class of of drill cuttings. М-БШ-02-2004. In Russian.

[10] Criteria for denomination of hazardous wastes to the hazard class for the environment. 2001. Approved by order of the Ministry of Natural Resources of the Russian Federation of June 15, 2001. № 511. In Russian.

[11] SR.2.1.7.1386-03. 2003. Sanitary Rules on determination of hazard class of toxic waste. In Russian. 